\title{
Flaws in Research Report Writing: An Evaluation of Research Reports Submitted for an International Conference on Education
}

\section{Ayoade Ejiwale Okanlawon*}

Department of Science, Technology and Mathematics Education, Faculty of Education, Osun State University, Ipetu-Ijesa Campus, Nigeria

\section{Abstract}

The present study was undertaken to assess papers presented during the $5^{\text {th }}$ International Conference organized by the Collaboration of Education Faculties in West Africa (CEFWA). This was done with a view to revealing participants' deficiencies in research report writing. The sample for the study comprised of 65 research reports submitted for peer review process by the conference participants. Data sources include reviewers' assessment of research report using the CEFWA Research Report Rating Scale (C3Rs-a five Likert scale) and reviewers' comments and suggestions on the weaknesses and strengths of the research reports. Based on these data sources, both descriptive statistics (e.g., mean) and content analysis of reviewers' evaluation comments were used in the data analysis. The results of the study revealed that (1) the journal-conference proceedings rejection rate was $47.7 \%$ (2) the Introduction and Discussion were rated as weak; Literature Review, Methodology, Results and Conclusion were rated

\footnotetext{
* Corresponding should be addressed to Dr. A. E. Okanlawon, Department of Science, Technology and Mathematics Education, Faculty of Education, Osun State University, Ipetu-Ijesa Campus, Nigeria
}

Email:drokanla@gmail.com

(Dhttps://orcid.org/0000-0002-6439-5852

(Received 14th January 2018; Revised 26 th July 2018; Accepted 20 th September 2018) (C) OUSL

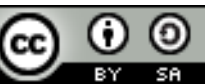

This article is published under the Creative Commons Attribution-Share Alike 4.0 International License (CC-BY-SA). This license permits use, distribution and reproduction in any medium; provided it is licensed under the same terms and the original work is properly cited. 
as fairly good; the titles and abstracts of submitted research reports were rated as good. Furthermore, the study revealed the following as the primary flaws associated with the Introduction, Literature Review, Methodology, Results and Discussion sections of the research reports: (1) improper focus on the study objectives and nonindication of gaps in knowledge (2) lack of attempt to critically critique the methods(s) used in previous studies (3) inadequate description of research designs (4) non-self-explanatory of tables and figures and (5) lack of discussion about the significance and implications of results. Based on the findings of this study, it was recommended that concerted efforts should be made by education faculties to organize faculty seminars where research report can be presented for constructive criticism. Also, universities and research institutions should endeavor to reward researchers for quality rather than quantity of their publications.

Key words: research reports, peer review process, journal rejection rate, editorial decision, journal editor

\section{Introduction}

In today's world, higher institutions of learning are established purposely to engage in teaching, carry out research and render services to the community. In fulfilling their responsibilities as researchers, specialists in different areas of study in the university community conduct research for various reasons. According to Moher\&Srivastava (2015), researches are conducted by the academic staff in higher institutions of learning for three main purposes: to share their findings with colleagues in the same field and others outside their areas of specialization, to influence current practices and/or policy within a specific discipline and to get their papers published in order to withstand the pressure of publish or perish slogan. This is because survival of lecturers in the universities and other tertiary institutions depends on the total number of publications they possess in reputable journals. Universities nowadays use a lecturer's authorship of printed referred research report as one of the major promotion criteria and standard (Bordage \& Caelleigh, 2001; Holliday, 2007).

The importance attached to publications in promoting lecturers accounted for fraudulent practices in which low quality research reports get their way into the journals (Kallestinova, 2011). Realizing the fact that publication is a major factor for getting promotion and receiving annual increment in salary, academic staff struggle to have both offshore and onshore publications. It has been observed that in some Nigerian universities the ratio of offshore to onshore 
publications is also taken into consideration during annual review of lecturers either for promotion or annual salary increment (Ahupa, 2014). In getting their research reports published, lecturers encountered some hindrances. As reported by Kleinert\& Horton, (2014), barriers to publication include: potential journals' unwillingness to publish the content considered to be inappropriate and very high journal rejection rates particularly in "luxury" journals. For instance, reputable journals such as Science Education, International Journal of Science Education, Journal of Research in Science Teaching, Chemistry Education Research and Practice, the American Biology Teacher, and the American Physics Teacher are few examples of journals in the field of science education with high rejection rates. In a bid to overcome these obstacles, various means have been adopted by desperate lecturers to get their papers published as publication is a major criterion for promotion. It is unfortunate that these lecturers are being assisted in fulfilling their intention by some so called professional associations that are floating journals with low rejection rate in an attempt to attract prospective authors to publish in their journals.

Many conferences are being organized by these 'predatory' associations both within and outside Nigeria with the intention of getting the lecturers' research reports published (Ahupa, 2014). This term, predatory, was first coined by librarian Jeffrey Beall at the University of Colorado, Deriver, USA having observed its prevalence (Butler, 2013). The term was used by him to describe publishers who engaged in the practice of publishing of research reports without the necessary quality controls, such as appropriate peer review and professional copy editing to ensure high-quality research. Regrettably, both inexperienced academics (who are unaware or eager for rapid promotion) and experienced academics (who intend to pad their curriculum vitae) patronize these questionable conferences (Wager, 2017). The issue of 'predatory' conferences is not peculiar to Nigeria. It is a global issue which is a serious concern to academics in different countries of the world (de Jager et al., 2017). Nowadays, many institutions have taken measures to prevent academics from falling prey to such events by carefully scrutinizing conference details before releasing university funds or grants for any international conferences.

These predatory associations went as far as adopting a strategy of repeatedly sending electronic mails inviting prospective authors to submit research reports for publication without any proper peer review process. Unsolicited and unwanted (spam) electronic invitations to speak at or attend conferences, or write for, or edit journals are a burgeoning aspect of academic life. However, there 
exist many recognized professional associations that organize conferences on contemporary issues on education. Unfortunately, they receive low patronage from the lecturers on the ground that their research reports of inferior quality might be rejected by these associations.

Although a plethora of research and literature (e.g., Girden\&Kabacoff, 2010; Rhodes, 2011; Pautasso, 2013) in education has attempted to ensure that there is quality in paper published in university based and associational journals, further studies are still needed in this direction. It should be noted that research focusing on peer review process as a means of harvesting quality research reports for publication in journals are still missing in the literature. Majority of the publications focused on describing peer review process, highlighting guidelines for reviewing research reports for educational journals and discussing essential qualities of editors and reviewers. Therefore, the present study aims at filling the existing gap in literature by assessing research reports presented and submitted during an international conference on education organized by the Collaboration of Education Faculties in West Africa (CEFWA). This is done with a view to identifying flaws in research reports writing submitted by the conference participants for peer review process. Only research reports that were presented during the plenary sessions and subsequently submitted by the authors for publication are subjected to peer review process by the editorial board. These research reports are either published in the refereed conference proceeding or the CEFWA journal based on the editorial decision regarding the research reports' quality. In some cases, conference participants may present research reports at the plenary sessions and decide to publish them elsewhere. Contrary to the best and common practice, CEFWA refereed conference proceedings are published alongside with the peer review journals after the conference. Both publications are subjected to the peer review process. Only the book of abstracts of conference papers is made available and the copies of the book are distributed to conference participants.

In this study, the guiding research questions are:

(1) What is the acceptance rate of research reports submitted for peer-review during 2014 CEFWA conference?

(2) How do the reviewers rate the various sections of the research reports submitted for peer-review?

(3) What are the common flaws in the research reports identified by the reviewers? 


\section{Literature Review}

The main objective of any research report is to properly communicate the author's findings to the readers (Walliaman, 2001). Writing a quality research report requires possession of good writing skills. The required writing skills are distinct and must be practiced in order to be fully competent in its discourse patterns. (Loseke $\&$ Cahill, 2004). Unfortunately, for most undergraduate students, research report writing skills are not satisfactorily taught (Showman et al., 2013). Inexperienced researchers tend to encounter problems in writing quality research reports (Wicherts, 2016). Different types of pitfalls are associated with different sections of research reports (Ali, 2010; Kowalczak et al., 2015).

The research reports are organized in such a way that the information flow from general to specific and then back to general. The Introduction presents the problem and provides general information while the Literature Review provides a critical appraisal of the previous studies related to research area under focus rather than a simple summary of prior studies. The Methodology provides the information by which a study's validity is judged while the Result section states the findings of the research arranged in a logical sequence. Section titled Discussion/Conclusion discusses the findings in a larger context. The following section describes each of these sections and their associated pitfalls in details.

Preceding the Introduction section are the Title and the Abstract. The title reflects the content of the research report. According to Peat, Mellis, Williams\&Xuan (2002), an effective title should possess the following characteristics: (1) identify the main issue of the paper (2) begin with the subject of the paper (3) is accurate, unambiguous, specific and complete, and (4) attract readers. Among the notable pitfalls commonly found in this section of a research report are: the title inadequately describes the article and the inclusion of unclear abbreviation and jargon in the title (Swales \& Christine, 2009).

An abstract is a concise, one-paragraph summary of the whole paper. Its length varies but seldom exceeds 200 words. A good abstract is expected to provide a complete synopsis of research objectives addressed, methods employed in proffering a solution to the problem, result obtained, conclusion drawn and implications of findings. Major errors commonly associated with an abstract are: (1) dissonance between the information in the abstracts and the information in the full text, (2) abstract exceeding maximum number of words allowed (Perneger \& Hudelson, 2004). 
The Introduction section is set aside for describing the nature of problem to be addressed and explaining why the study is of interest. As viewed by the American Chemical Society (2006), a well-written Introduction in any research report is a clear statement of the problem and the rationale for embarking on the specific study. A good Introduction is expected to fulfill the following purposes as specified by Biggam (2011): (1) provide preliminary background information to place the present study in context (2) clarify the focus of the study (3) specify the overall research objective (4) specify what has been done, what has not been done and what still needs to be done. When the Introduction of a research report fails to describe the purpose and objective of the study and in addition, contains materials irrelevant to the study or belonging to other sections of the research report, then such an Introduction can be assessed to be deficient (Gupta, 2017).

The Literature Review section situates an existing literature in a broader scholarly and historical context. The purpose of a Literature Review is to describe past important research and relate it specifically to the research problem. This section includes all relevant findings from two credible sources which are the conceptual literature and the research literature. Significant pitfalls usually associated with this section is reflected in the inability of the research report writer to (1) compare and contrast findings from different studies (2) compare and contrast methodologies used to arrive at those findings (3) critique the methodologies, noting important strengths and weaknesses and (4) suggest extension of the studies (Weber et al., 2002). Similarly, Lee et al. (2013) observed that emerging researchers when writing a Literature Review simply report previous research results without relating them to the current findings.

The Methodology section typically features a description of the population and sample that were involved, the study design, and the instrument used, the data collection procedure and the data analysis technique. The Methodology section is the most important aspect of a research paper because it provides the information by which the validity of a study is ultimately judged (Shattell et al., 2010). Therefore, the researcher must present this section in such a way that these two important questions are properly addressed: (1) how were the data collected or generated? (2) how were they analyzed? The most commonly found errors associated with this section are poor reporting of statistical methods and inadequate description of data collection procedure thereby preventing replication of the study (Shea ., 2001; Fox et al., 2016).

The Results section is specifically designed for the presentation of tabular or graphic summary of research findings, listed under headings in accordance with the formulated research question. For many authors, writing the Results section is more intimidating than 
writing the Methodology (Gallo et al., 2014). The results of the study carried out should be presented in a consistent manner to the reader. In presenting results visually, Kallestinova (2011) offered the following guidelines: (1) graph and tables should be used to reveal trends in the data, but they must be explained and referred to in adjacent accompanying text and (2) figure and tables should be used to summarize, amplify or complement information already given in the text. In a bid to advise postgraduate students, Murray \& Hughes (2008) highlighted some common errors to be avoided such as incomplete and/selective reporting of findings, presenting reports from different studies and illogical presentation of findings.

The Discussion section is conceived as the counterpart to the introduction since this part should lead the reader from narrow and very specific results to more general conclusions (Lovejoy et al., 2011). It is often the most difficult section of research report to write. A well-written discussion section includes a statement of important results, reference to previously published and relevant literature, comparison of study results with previously reported findings, explanation of result, elucidation of strengths and weaknesses of the study and description of impact of the study.

The Conclusion section introduces the work, briefly states the major results and the major points of the discussion. This aspect finally ends with a statement of how the present research contributes to the overall field of study. As advised by Young (2003), authors of research reports should guard against the following mistakes when discussing findings (1) failure to locate present results in the context of finding from other studies (2) overstating the implications of the results and (3) failure to describe the limitation of the study.

The Reference section typically features an alphabetical list of the sources consulted during the conduct of the study. Each reference related to a journal is expected to reflect the names(s) of author(s), title of the paper, journal name, volume number of the issue in which the article appeared, starting page number, end page number and year of publication. In the case of a book, its author(s), title, publisher's name, place of publication, year of publication and edition are expected to be given. Some common pitfalls associated with this section are: (1) omission of some references that have been cited in the text. (2) references are out of date or cannot be accessed by most readers (Dernt1,2014).

Despite the fact that certain sections of research report are difficult to write, academics are required to publish quality work in reputed journals. This is because the development and progress in any 
profession, including teaching is strongly influenced by publications in academic journals. As observed by Balster (2017) and Christenbery (2011), publication in academic journals has two main advantages. First, it provides professionals with an opportunity to share their research-based practices and research result with colleagues in the discipline. Second, academic publications serve as a source of knowledge for students, novice teachers and emerging researchers. Such benefits can only be derived from quality research reports. To this end, appropriate scrutiny of research reports submitted to academic journals to ascertain their worth, methodological rigour and utility before appearing in the print media and online publications is very essential. In order to ensure that reliable and quality research reports are published in academic journal, most journals put in place peer review process (Bordage, 2001; Ghahramani, \& Mehrabani, 2013).

The peer review process has long been the mechanism of ensuring high quality research in academia (Lee, Sugimoto, Zhang \& Cronin, 2013). It is the process by which expert's advice editors on the value of research reports submitted for publication (Smith, 2006). Reviewing is more than just grading; it is a means of improving the quality of research report (Fox, Burns\& Meyer, 2016). As advised by Hames (2007), it is unethical for a reviewer to allow a seriously flawed research report to escape unchallenged into the peer reviewed journal, where it will be a trap to the emerging researchers and students who will read the research report superficially and will simply accept flawed conclusion at face value.

\section{An overview of the CEFWA peer review process}

The peer review process varies slightly from journal to journal. CEFWA uses a peer review process (Fig. 1) essentially as a quality control mechanism. Research reports featured in the CEFWA publications are obtained only through yearly organized conferences. For a research report to be published in the CEFWA journal or refereed conference proceedings, the usual procedure for an author is to submit a copy of the research report to the conference's Local Organizing Committee (LOC) after presentation at the plenary session. If, after an initial superficial screening by the journal editor, the research report appears to be appropriate to the journal's aims and scope, the editor will send it to two reviewers. These reviewers are very often faculty members at universities who are known to be knowledgeable in the area pertaining to the research report. These reviewers provide the editor with a written evaluation of the research report along with their recommendations as to whether or not the editor should publish the article. It is quite common for these 
reviewers to suggest possible modifications of the research report in order to meet the standards for publication. The editor must then send the reviewers' comments and suggestions with an editorial decision to the author. If the research report receives a totally good evaluation from the reviewers, it will very likely be published in either journal or refereed conference proceedings (perhaps after some revisions).

Categorization of accepted research reports into those to be featured either in the CEFWA journal or conference proceedings is based on the quality of the research report as judged by editorial advisory board using the criteria such as originality $(40 \%)$, relevance $(30 \%)$, timeliness (15\%) and critical pertinent problem addressed (15\%).Based on these criteria, only research reports with assessment score of $60 \%$ and above are eligible to feature in the CEFWA journal. If the editor receives mixed reviews, the author might be asked to do a major revision of the research report and to resubmit it for publication. Sometimes, if the reviews are very poor, or if the periodical has too many submitted research reports or if the editor does not feel the article fits in with editorial policy, the author is informed that the article has been rejected. However, in a situation where research reports were rejected on the ground of space limitation, authors are advice by the CEFWA editor to submit the rejected research reports to another journal within the CEFWA member faculties. 


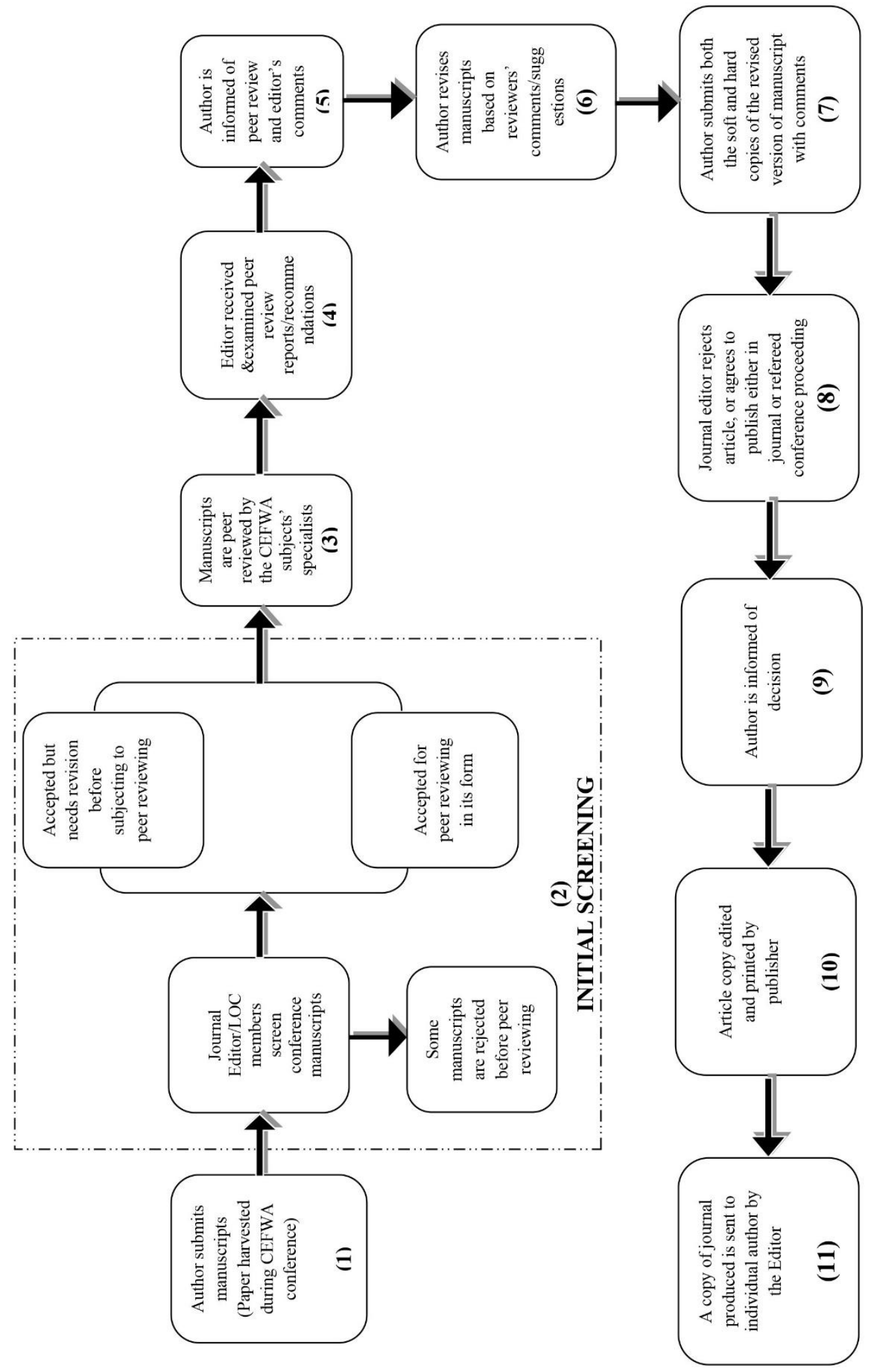

Figure 1. CEFWA Peer Review process for journal publication 


\section{Methodology}

A mixed methods research design is adopted in this study as the study involves collecting, analyzing and interpreting both quantitative and qualitative data that are essential in addressing the research questions. It was conducted in the month of September,

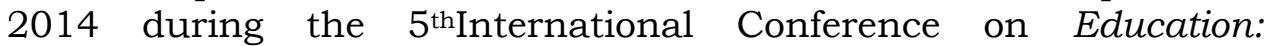
Innovation, Policy Implementation and Challenges organized by the CEFWA. The total number of the registered participants for the conference was $246(n=246)$ and was far greater than the number of the research reports presented $(n=108)$ during the conference. Some participants numbering 138 attended without presenting any research report. Out of the presenters $(n=108), 43$ decided to publish the research reports elsewhere and only 65 submitted their research reports for the peer review. Hence, the study sample consisted of all the research reports submitted by the conference participants for the peer-review process totaling $65(n=65)$.

The CEFWA Research Report Reviewers' Evaluation Form (C3RsEF) was used as the main data collection instrument to collect data from the submitted research reports. It comprised two sections (A and $B$ ). Section A, the CEFWA Research Report Rating Scale (C3Rs), is a five point-Likert scale consisting of 35 items attached to a scale ranging from, 'very good' to 'very weak' with 'fairly good' as the pivotal of the scale. It was designed to collect information regarding the quality of various sections of the research reports as assessed by the reviewers. Section B demands open responses relating to the reviewers' general comments and suggestions for improvement on the various sections of the papers submitted.

Section A of the C3RsEF had eight sections with a total number of 35items. These sections are: Title (2 items), Abstract (2 items), Introduction (10 items), Review of related Literature (2 items), Methodology (3 items), Results and Interpretations (3 items), Discussion (4 items), Conclusion and Implication (4 items). The remaining items deal with research report layout guidelines based on the CEFWA journal policy for research reports preparation. These items are criteria developed to guide the reviewers' comments and assessments regarding the research reports' reliability, originality, relevance, appropriateness of the data analysis technique, suitability of the data collection procedure and appropriateness to the journal's aims and scope. Before its adoption by the CEFWA, it was validated by a five-member panel of experts (author, reviewer, editor, publisher and funding agency) constituted by the CEFWA editorial board. In addition, the scale has a satisfactory and acceptable Cronbach's alpha reliability coefficient of 0.86 . 
The needed data from the submitted research reports were obtained through reviewer's rating of quality of participant research reports using the following scale: very good (4), quite good (3) fairly good/average (2), quite weak (1), very weak (0). On this scale, quite good and fairly good could be interpreted as 'good' and 'mediocre' respectively. Initially, 53 assessors were purposively selected by the Local Organizing Committee (LOC) from 12 Faculties of Education to assess the quality of research reports submitted. Their selection was based on the criteria specified by Murray \& Hughes (2008), and Balster (2017): (1) they are knowledgeable about a specific field of study (2) they possess specialized knowledge of the potential advantages and pitfalls of various research approaches and are capable of reviewing within time frame and writing constructive comments on the research reports received. Finally, 48 reviewers were selected by the editor taking into consideration the reviewers' experience and reputation, and evidence of having published on the same topic to be assessed. Reviewers were not randomly selected from the initial pool of reviewers in order to avoid a situation whereby a research report would be judged by those who are less capable. Being an active member of the Local Organizing Committee (LOC), gave the researcher great opportunity of having access to the data used in this study.

The data collected from the rating scale were analyzed using a descriptive statistic in form of mean (quantitative) while the nonnumerical data (Section B of the CEFWA Research Report Reviewers' Evaluation Form) reviewers' comments on different aspects of research reports) were analyzed using contents analysis. This type of analysis is used when a researcher wants to analyze a written or spoken record for the occurrence of specific categories of events, items or behavior. Hence, its usage is relevant in this study. Prior to the actual content analysis process, two coders (two experienced reviewers) independently coded samples of reviewers' comments retrieved from the CEFWA archive, compared categories, and resolved differences via discussion. This preliminary coding exercise was done with a view to prepare the coders for the actual content analysis. Thereafter, the currently harvested reviewers' comments were read and re-read by the two coders in order to gain deep understanding of the reviewers' comments. Based on the coders' understanding of the ideas expressed by the reviewers', flaws reported by the reviewers were assigned to categories which correspond to different sections of a research report. The coding performed by the coders largely coincided, but little variations in coding were discussed and adjusted. The results of reliability test showed an acceptable level of inter-rater agreement of $82 \%$ (concordance) between the two coders. In order to ensure confidentiality in reporting the findings, the reviewers' comments regarding the papers' quality were reported using a letter 
code (e.g., R1). The results were presented in Tables for easy interpretation.

\section{Results and Discussion}

The analysis of the reviewers' reports yielded the results concerning the acceptability of the research reports submitted for publication as presented in Table 1 . The reviewers' assessment reports which emerged from the ratings of research report quality were analyzed in accordance with the research report structure. The mean values of the reviewers' rating of each section of the research report are shown in Table 2 and interpreted accordingly. For ease of reference, the results presented in Tables are discussed according to the three research questions that provided direction to this study.

\section{Answering research questions:}

(1) Research Question 1. What is the journal-conference proceedings acceptance rate of research reports submitted for peer-review during 2014 CEFWA conference?

Table 1. Acceptance rate (by number of authors) of research reports submitted for the Journal and conference proceedings publications

\begin{tabular}{|l|l|l|l|l|}
\hline \multirow{2}{*}{ Editor's Decision } & \multicolumn{2}{|l|}{ Number of authors } & \multirow{2}{*}{ Total } \\
\cline { 2 - 5 } & Single & Two & Multiple & $0(0.0 \%)$ \\
\hline $\begin{array}{l}\text { Research report accepted } \\
\text { outright }\end{array}$ & - & - & - & $13(20.0 \%)$ \\
\hline $\begin{array}{l}\text { Research report accepted with } \\
\text { minor revisions }\end{array}$ & 8 & 4 & 1 & $21(32.3 \%)$ \\
\hline $\begin{array}{l}\text { Research report accepted with } \\
\text { major revisions }\end{array}$ & 10 & 7 & 4 & $31(47.7 \%)$ \\
\hline Research report rejected & 18 & 8 & 5 & $\begin{array}{l}65 \\
(100.0 \%)\end{array}$ \\
\hline Total & 36 & 19 & 10 & \\
\hline
\end{tabular}

Whenever CEFWA sends research reports to reviewers, they are expected to provide comments and suggestions on the submission, which are then sent to the author with editorial decision. As shown in Table 1, editorial decisions fall into four main categories: (i) accept without changes (2) decline for now, future acceptance very likely (3) decline for now, future acceptance possible and (4) reject, do not resubmit. Based on the data presented in Table 1, 0.0\%, 20.0\%, $32.3 \%$ and $47.7 \%$ fell in category one, two, three and four 
respectively. To have a research report accepted after its initial screening is rare even for experienced authors. The finding of no research report falling in the category of "research report accepted outright" after reviewers' rating is not surprising (Rozas \& Klein, 2010: Smart et al., 2013) because hardly can one submit a research report for peer review without flaws. Thus, peer review is not merely a difficult stage to get one's research report published in highly rated journal. It is as much an academic avenue to obtain advice, support and assistance from colleagues in the same field (Cormode, 2013). Only $20.0 \%$ of the research reports requires minor revision. In this situation, the editor supports the reviewers' comments regarding its strengths and weaknesses. Hence, there is need for revision, which may be subjected to re-review before acceptance. Non-conformity to journal referencing style, grammatical and typographical errors, and unsatisfactory explanation of certain points were observed in research reports in the category. The proportion of research reports that required major revision is $32.3 \%$. The editor's decision to request major revision for $32.3 \%$ of the research report is due to the fact they have potential merit and if they are thoroughly revised by addressing all deficiencies, they are likely to be published.

Table 1 revealed that the journal-conference proceedings rejection rate for the year 2014 is $47.7 \%$. The value implies that almost $50 \%$ of the research reports were rejected. It is obvious that the higher the acceptance rate, the higher the probability of a research report being accepted. The inferior quality of most of the research reports presented accounts for the value of the journal-conference proceedings rejection rate reported in this paper. Referring to the peer review process that yielded the data presented in Table 1, most research reports were rejected by the CEFWA editors based on reviewers' negative comments. It is understandable that if a research report is rejected, its reviewers' narrative comments are quite beneficial to the author in improving the quality of the relevant research report. Most of the research reports were mainly rejected due to the fact that they contained serious flaws in research design, methodology and data analysis techniques. In addition, they were rejected because their contributions to the field were assessed by the reviewers to be sufficiently insignificant in the sense that they appeared to offer nothing new to the existing knowledge. Furthermore, most of the research questions raised to provide directions for the study in rejected research reports were not of interest to the field because they failed to address a serious education problem facing the West Africa sub-region.

In a year, CEFWA can normally produce two journal issues and one referred conference proceedings. Averagely, this cannot accommodate more than 34 quality research reports based on the journal policy. However, with the author's consent, CEFWA editors do forward a 
rejected research report with its reviewers' comments to another journal outlet within the consortium (i.e., journals within the Education Faculties that are CEFWA members) with the hope of getting them published after thorough revision.

Research Question 2. How do the reviewers rate the various sections of the research reports submitted for the peer-review process?

Table 2. Reviewers' rating of the quality of participants' research reports and samples of major flaws identified in the submitted research reports using the CEFWA Research Report Evaluation Form

\begin{tabular}{|c|c|c|c|c|}
\hline $\mathbf{S} / \mathbf{N}$ & $\begin{array}{l}\text { Paper } \\
\text { structure }\end{array}$ & $\begin{array}{l}\text { Cluster } \\
\text { Mean }\end{array}$ & Rating & Sample of major flaws \\
\hline 1 & Title & 3.40 & $\begin{array}{l}\text { Quite } \\
\text { good }\end{array}$ & $\begin{array}{l}\text { (i) title needs to be revised for } \\
\text { clarity } \\
\text { (ii) purpose and scope of the study } \\
\text { not clearly captured in the title. } \\
\text { (iii) title not clearly inform the } \\
\text { reader of the contents within. }\end{array}$ \\
\hline 2 & Abstract & 3.45 & $\begin{array}{l}\text { Quite } \\
\text { good }\end{array}$ & $\begin{array}{l}\text { (i) abstract not precise } \\
\text { (ii) sufficient information describing } \\
\text { the topic, scope, instrument, data } \\
\text { analysis, key findings and } \\
\text { recommendations not provided. }\end{array}$ \\
\hline 3 & $\begin{array}{l}\text { Introducti } \\
\text { on }\end{array}$ & 1.86 & $\begin{array}{l}\text { Quite } \\
\text { weak }\end{array}$ & $\begin{array}{l}\text { (i) nature of the problems } \\
\text { investigated and why it is of interest } \\
\text { were not properly conveyed to the } \\
\text { reader. } \\
\text { (ii) gaps in knowledge left out. } \\
\text { (iii) research questions lacked } \\
\text { novelty. }\end{array}$ \\
\hline 4 & $\begin{array}{l}\text { Literature } \\
\text { Review }\end{array}$ & 2.55 & $\begin{array}{l}\text { Fairly } \\
\text { good }\end{array}$ & $\begin{array}{l}\text { (i) simply paraphrasing precise } \\
\text { studies. } \\
\text { (ii) very little or no attempt to } \\
\text { critically critique the method(s) } \\
\text { used in previous studies } \\
\text { (iii) failure to capture findings for } \\
\text { different studies. }\end{array}$ \\
\hline 5 & $\begin{array}{l}\text { Methodolo } \\
\text { gy }\end{array}$ & 2.87 & $\begin{array}{l}\text { Fairly } \\
\text { good }\end{array}$ & $\begin{array}{l}\text { (i) flaw methods of sampling } \\
\text { (ii) instruments incompletely } \\
\text { described } \\
\text { (iii) unclear statistical techniques } \\
\text { (iv) procedure for data collection not } \\
\text { self-explanatory }\end{array}$ \\
\hline 6 & Results & 2.71 & $\begin{array}{l}\text { Fairly } \\
\text { good }\end{array}$ & $\begin{array}{l}\text { (i) presented with unclear and } \\
\text { inappropriate captions in some } \\
\text { cases. } \\
\text { (ii) tables not self-explanatory } \\
\text { (iii) results not presented clearly } \\
\text { and concisely }\end{array}$ \\
\hline
\end{tabular}




\begin{tabular}{|c|l|l|l|l|}
\hline & & & $\begin{array}{l}\text { (iv) the most important findings not } \\
\text { properly summarized in starting } \\
\text { discussion. } \\
\text { (v) contrast of remarkable findings } \\
\text { with earlier findings was left } \\
\text { undone. } \\
\text { (vi) extent to which the findings } \\
\text { resolved the problem(s) addressed } \\
\text { is not clearly discussed. }\end{array}$ \\
\hline $\mathbf{7}$ & Discussion & 1.77 & $\begin{array}{l}\text { Quite } \\
\text { weak }\end{array}$ & \\
\hline $\mathbf{8}$ & Conclusion & 2.48 & $\begin{array}{l}\text { Fairly } \\
\text { good }\end{array}$ & \\
\hline $\mathbf{9}$ & Reference & 2.83 & $\begin{array}{l}\text { Fairly } \\
\text { good }\end{array}$ & \\
\hline
\end{tabular}

The results of the reviewers' assessment of the participants' research reports are presented in Table 2. The Title $(\mathrm{M}=3.40)$ and Abstract $(\mathrm{M}=3.45)$ were rated by the reviewers as quite good, the Introduction $(\mathrm{M}=1.86)$ and Discussion $(\mathrm{M}=1.77)$ sections were rated as quite weak, sections on the Review of related Literature $(\mathrm{M}=2.55)$, Methodology $(M=2.87)$, Results $(M=2.71)$, Conclusion $(M=2.48$ and Reference were (2.83) rated by the reviewers as quite weak. The cluster mean value for each section of the research report was determined from the mean scores for the items of the CEFWA Research Report Rating Scale (C3Rs). The basic principle of Likert Scale measurement was applied in calculating the item mean. This principle states that scores yielded by a Likert scale are composite (summated) scores derived from an individual's responses to the multiple items on the scale (Oppenhein, 1992; Kline, 1998). Samples of major flaws shown in Table 2 are commonly observed flaws as revealed in the reviewer's comment (Section B of CEFWA Research Report Evaluation Form).

As shown in Table 2, the Introduction and Discussion sections were rated low by the reviewers. Low ratings of these sections were due to defects identified in the research reports submitted for peer review. This result supported Holliday's (2007) submission that writing the Introduction aspect of a research report is a difficult task for the emerging researchers. According to Biggam (2011), writing quality Introduction requires the writer to perform many complex tasks such as: (1) providing preliminary background information to place the current study in context (2) clarifying the focus of the present study (3) specifying the general and specific purposes of the study and (4) pointing out value of the research. In this research, it was also found that the Discussion sections were inferior in quality. This finding is in consonance with the Kallestinova's (2011) argument that writing a Discussion section is as difficult as writing the Introduction section of a research report. Kallestinova further stressed that the 
uniqueness of every research report in terms of its methods and findings is the key factor that accounts for the difficulties encountered by young researchers.

Research Question 3. What are the common flaws in the research reports identified by the reviewers?

Research question 3 is resolved by subjecting the reviewers' comments and suggestions to content analysis through which deficiencies in various sections of the research reports reviewed were identified. A few examples of flaws identified through the content analysis were presented in Table 2 while samples of the reviewers' comments and suggestions regarding the quality of various sections of the research reports are presented in Table 3.

Table 3. Samples of the reviewers' comments and suggestions regarding the quality of various sections of research reports

\begin{tabular}{|c|c|}
\hline Section & Reviewers' comments and suggestions \\
\hline Title & $\begin{array}{l}\text { "title is rather too long. Not specific and } \\
\text { informative enough" (R21) } \\
\text { "restructure the title; that is make it precise in order to } \\
\text { inform readers about the content therein". (R19) }\end{array}$ \\
\hline Abstract & $\begin{array}{l}\text { "abnormal length' it exceeded } 250 \text { words due to inclusion } \\
\text { of irrelevant information" (R15). } \\
\text { "provide sufficient information describing the instrument } \\
\text { used, the principal findings and the key } \\
\text { recommendations in your abstract" (R7). }\end{array}$ \\
\hline Introduction & $\begin{array}{l}\text { "in revising this section, address the following question } \\
\text { (1) why are you interested in this topic? (2) why is this } \\
\text { topic worth investigating? Clearly furnish the readers the } \\
\text { current state of knowledge on your topic: your review } \\
\text { failed to properly situate your work within current } \\
\text { studies" (R11) } \\
\text { "your introduction is too lengthy. Be brief and let the } \\
\text { reader comprehend what your research is all about. It is } \\
\text { difficult for me to understand the rationale for this } \\
\text { study".(R5) }\end{array}$ \\
\hline $\begin{array}{l}\text { Literature } \\
\text { Review }\end{array}$ & $\begin{array}{l}\text { "what I am expecting to see in this part I did not see it. } \\
\text { Presenting catalogue of summaries of selected previous } \\
\text { studies is not okay. (R23) }\end{array}$ \\
\hline
\end{tabular}




\begin{tabular}{|c|c|}
\hline & $\begin{array}{l}\text { "inadequate; your review must go beyond presenting } \\
\text { summaries of related studies, combine findings from } \\
\text { various studies reviewed into an integrative pattern to } \\
\text { improve quality of your review" (R8) }\end{array}$ \\
\hline Methodology & $\begin{array}{l}\text { "the employed study design and procedure for data } \\
\text { collection are not sufficiently transparent" (R13) } \\
\text { "make your methodology section explanatory enough for } \\
\text { the reader. Sampling technique employed inappropriate, } \\
\text { preferably stratified sampling techniques will be suitable } \\
\text { in this study" (R9) }\end{array}$ \\
\hline Results & $\begin{array}{l}\text { "rather than presenting your results in prose form, it is } \\
\text { better to use tables or graphics" (R17) } \\
\text { "tables carrying inappropriate headings" } \\
\text { (R3) }\end{array}$ \\
\hline Discussion & $\begin{array}{l}\text { "your findings are not properly accounted for. No } \\
\text { discussion of findings. Enrich this section by clearly } \\
\text { explaining the significance of your findings within the } \\
\text { context of other research" (R12) } \\
\text { "not logically presented; my expectation } \\
\text { is that your summary of major findings } \\
\text { should be followed by the discussion of } \\
\text { the importance of the study's findings" } \\
\text { (R10) }\end{array}$ \\
\hline Conclusion & $\begin{array}{l}\text { "not satisfactory and it failed to present the key findings } \\
\text { of the study. It will be alright if direction for future } \\
\text { research is suitably expressed". (R6) } \\
\text { "this section can still be done in a better way, value will } \\
\text { be added to this work if its contributions to field of } \\
\text { biology education are emphasized" (R4) }\end{array}$ \\
\hline References & $\begin{array}{l}\text { "this section is not properly done. The reference list is a } \\
\text { mix of different styles. Follow the APA referencing format } \\
\text { and include all the in-text citations in the reference list. } \\
\text { Mismatch between in-text citations and reference list } \\
\text { should be corrected (e.g Bello (2000); Bello (2001); } \\
\text { Oguniyi (2008); Ogunniyi (2008)" (R24) } \\
\text { "Inadequate; many citations not listed. } \\
\text { Do not conform to APA format". (R22) }\end{array}$ \\
\hline
\end{tabular}

The preceding results revealed that papers reviewed contained flaws of different types which cut across different sections of research 
reports. This corroborates with the existing literature (Pautasso, 2013; Bavdekar, 2015) that reported that most of the rejected papers or papers considered for major revision consisted of many pitfalls. Authors not listing the study limitations, discussing observation not reported in the Results section, Conclusion not supported by data and making recommendations that are not based on the findings are few examples of reported pitfalls.

\section{Conclusion and Implications}

This study sets out to identify flaws in research report writing through assessing research reports submitted during an international conference on education organized by CEFWA. The results revealed that the journal-conference proceedings rejection rate for the year 2014 was $47.7 \%$. In reviewers' rating of the different sections of research reports, the Introduction and Discussion sections were rated very low in terms of quality. As revealed in the study, deficiencies in the research reports which accounted for the inferior quality of submitted papers are: (a) title not clearly informing the reader of the content of the writing, (b) study objectives not welladdressed, (c) gaps in knowledge not properly indicated, (d) research questions lack novelty, (e) insufficient methodological explanation, (f) incomplete description of research tools, and $(\mathrm{g})$ results presented not self-explanatory enough. In the author's view, it is possible to remove or minimize flaws in research report prepared for submission if the authors can take the following precautions. (1) reading each section of the research report individually in order to ensure that it contains necessary information and that the research report's contents convey the information in a concise manner. (2) seeking the assistance of colleagues within and outside the author's field in reading the research report with a view to providing constructive feedback and checking for logical flow of ideas.

The educational implication is that there is need for departmental and faculty seminars in the education faculties which can serve as avenue for training in research report writing. Professional associations in the field of education can also assist in this direction by organizing workshops on research report writing targeting both academic staff members and postgraduate students. In such workshops, experienced reviewers and journal editors can be used as resource persons to give specific training on various sections (e.g. Abstract, Introduction) of research reports. 


\section{References}

Ali, J. (2010). Manuscript rejection: causes and remedies. Journal of Young Pharmacists, 2 (1), 3-6. doi:10.4103/0975-1483.62205.

Ahupa, B. F. (2014). Reforms and implications for best practices in University annual review exercise, Ibadan, Nigeria: Chadik Press.

American Chemical Society (2006). ACS style guide: Effective communication of Scientific information (3rd Ed.) ACS, Washington, DC.Society and Oxford University Press.

Balster, R. L. (2017). Reviewing manuscripts for scientific journals. In T.F. Babor, K. Stenius, R. Pates, M. Miovsky, J.O'Reilty, \& P. Candon (Eds.), Publishing addiction science: A guide for the perplexed, 3rd edition (pp. 245-263). London: Ubiquity Press Ltd. doi: 10.5334/bbd.m.License:CC-BY 4.0

Bavdekar, S. B. (2015). Writing the discussion section: Describing the significance of the study findings. Journal of the Association of Physicians of India, 63 (5), 40-42.

Biggam, J. (2011). Succeeding with your master's dissertation: A stepby-step handbook England: Open University Press.

Bordage, G. (2001). Reasons reviewers reject and accept manuscripts: The strengths and weakness in medical education reports.Academic medicine, 76 (9), 889-896.

Bordage, G. \& Caelleigh, A. (2001). A tool for reviewers: Review criteria for research manuscripts. Academic Medicine, 76(9) 897-978.

Butler, D. (2013). Investigating journals: The dark side of publishing. Nature, 395 (7442), 433-435.

Christenbery, T. L. (2011). Manuscript peer review: a guide for advanced practice nurses. Journal of the American Academy of Nurse Practitioners, 23(1), 15-22.

doi: $10.1111 / \mathrm{j} .1745-7599.2010 .005442 . x$

Cormode, G. (2013). What does an associate editor actually do? SIGMOD Record, 42 (2) 52-58. 
De Jager, P., de Kock, F., \& Van der Spuy, P. (2017). Do not feed the predators. South African Journal of Business Management, 48 (3), 35-45.

Derntl, M. (2014). Basics of research paper writing and publishing. International Journal of Technology Enhanced Learning, 6 (2), 105-123.

Fox, C. W., Burns, C. S. \& Meyer, J. A. (2016). Editor and reviewer gender influence the peer review process but not peer review outcomes at an ecology journal. Functional Ecology, 30 (1), 140153.

Gallo, S. A., Carpenter, A. S., Irwin, D., McPartlant, C. D., Travis, J., Reynders, S. Thompson, L. A. \& Glisson, S. R. (2014). The validation of peer review through research impact measures and the implications for funding strategies.PLoS ONE, 9(9), 1015. doi:10.1371/journal.pone.0106474

Ghahramani, Z., \&Mehrabani, G., (2013): The criteria considered in preparing manuscripts for submission to Biomedical Journals. Bulletin of Emergency and Trauman, 1(2), 56-59.

Girden, E. R., \& Kabacoff, R. I. (2010). Evaluating Research Articles: From start to finish, 3rd edition. Thousand Oaks, CA, London: Sage Publications.

Gupta, V. K. (2017). Quality control through peer review process in scholarly communication: Review of related literature. IRAInternational Journal of Management and Social Sciences, 8 (3), 248-255.

Hames, I. (2007). Peer review and manuscript management in scientific journals: Guidelines for good practice. Hoboken NJ: Wiley-Blackwell.

Holliday, A. (2007). During and writing qualitative research, 2nd edition. Thousand Oaks, CA London SAGE Publications Ltd.

Kallestinova, E. D. (2011). How to write first research paper.Yale Journal of Biology and Medicine, 84 (3) 181-190.

Kleinert, S., \& Horton, R, (2014). How should medical science change? Lancet, 38 (3), 197-198.

doi:10.1016/SO 140-6736(13)62678-1 


\section{A. E. Okanlawon}

Kline, P. (1998). The new psychometrics: Science, psychology and measurement(1stEdition). New York, NY: Routledge.

Kowalczuk, M. K., Dudbridge, F., Nanda, S., Harriman, S. L., Patel, J. \& Moylan, E. C. (2015). Retrospective analysis of the quality of reports by author-suggested and non-author-suggested reviewers in journals operating on open or single-blind peer review models.BMJ open, 5(9), 1-9. doi:10.1136/bmjopen2015-008707

Lee, C. J., Sugimoto, C. R., Zhang., G. \& Cronin, R. (2013). Bias in peer review. Journal of the American Society for Information Science and Technology, 64 (1), 2-17.

Lovejoy, T. I., Revenson, T. A., \& France, C. R. (2011). Reviewing manuscripts for peer review journals: A primer for novice and seasoned reviewers. Annals of Behavioural Medicine, 42(1), 1 13. doi: $10.1007 / \mathrm{s} 12160-011-9269-\mathrm{x}$

Loseke, D. \& Cahill, S. (2004). Publishing qualitative manuscripts: lessons learned. In C.Seale, G. Gobo, J. Gubrium\& D. Silverma (eds) Qualitative Research Practice, London: sage.

Moher, D., \& Srivastava, A. (2015). You are invited to submit... BioMed Central, 13, 180-184.

doi: $10.1186 /$ s 12916-015-0423-3

Murray, N., \& Hughes, G. (2008). Writing up your university assignments and research projects: A practical handbook, Maidenhead:McGraw-Hill Open University Press.

Oppenheim, A. N. (1992). Questionnaire design, interviewing, and attitude measurement.London: Printer Publishers. doi:10.1002/casp.2450040506

Pautasso, M. (2013). Ten simple rules for writing a literature review. PLOS Computational Biology, 9 (7), 1-4. doi:10.1371/journal.pcbi.1003149

Peat, J., Mellis, C., Williams, K. \& Xuan, W. (2002). Health Science Research: A Handbook of Quantitative methods, London: Sage.

Perneger, T. V., \& Hudelson, P.M. (2004). Writing a research article: advice to beginners. International Journal for Quality in Health Care, 16 (3), 191-192. 
Rhodes, E. A. (2011). A commentary on literature reviews Volta Reviews, 111 (3), 353-368.

Rozas, L. W. \& Klein, W. C. (2010). The value and purpose of the traditional qualitative literature review. Journal of EvidenceBased Social Work, 7 (5), 382-399.

Shattell, M., Chinn, P., Thomas S. \& Cowling, W.R. (2010). Authors' and editors' perspective on peer review quality in three scholarly nursing journals.Journal of Nursing Scholarship, 42(1), 58-65. doi: 10.1111/j.1547-5069.2009.01331.x

Shea, J. A., Caelleigh, A. S., Pangaro, L. \& Steinecke, A. (2001). Review process. Academic Medicine, 76 (9), 911-914.

Smart, P., Maisonneuve, H., \& Polderman, A. (Eds.). (2013). Science Editor's Handbook, 2cd edition. Cornwall, UK: European Association of Science Editors (especially Section 4).

Smith, R. (2006). Peer review: A flawed process at the heart of science and journals. Journal of the Royal Society of Medicine, 99(4), 178-182. doi: 10.1258/jrsm.99.4.178.

Showman, A., Cat, L. A., Cook, J., Holloway, N \& Wittman, T. (2013). Five essential skills for every undergraduate researcher. Council on Undergraduate Research Quarterly, 33(3), 16-20.

Swales, J. M. \& Christine, B. F. (2009). Abstracts and the writing of abstracts. Ann Arbor, MI: University of Michigan Press, Inc.

Wager, E. (2017). Why we should worry less about predatory publishers and more about the quality of research and training at our academic institutions. Journal of Epidemiology, 27(1), 87-88.

Weber, E.J., Katz, P.P., Waeckene, J. F. \& Callaham, M. L. (2002). Author perception of peer review: impact of review quality and acceptance of satisfaction. Journal of the American Medical Association, 287(21), 2790-2793.

doi:10.1001/jama.287.21.2790

Wicherts, J. M. (2016). Peer review quality and transparency of the peer-review process of open access and subscription journal. PLoS ONE, 11 (1), 1-19. doi:10.137/journal.pone.0147913 
A. E. Okanlawon

Walliman, N. (2001). Your research projects.A step-by-step guide for the first-time researcher. London, England: sage publications.

Young, S. N. (2003). Peer Review of manuscripts: theory \& practice. Journal of Psychiatry Neuroscience, 28 (5), 327-330. doi: 10.193978/jpn.1451.7575 